\title{
Multiple Output Flyback Converter Design
}

\author{
Richard Zelnik ${ }^{1)}$ and Michal Prazenica ${ }^{2)}$ \\ 1) 2) Faculty of Electrical Engineering and Information Technology, University of Zilina, Zilina, Slovakia, \\ e-mail: ${ }^{1)}$ richard.zelnik10@gmail.com, ${ }^{2)}$ prazenica@fel.uniza.sk
}

\begin{abstract}
DC-DC converters are mainly used to provide required output voltage by suitably controlling the pulse width modulated (PWM) signal given to the gate of the fastacting power electronics switches. The flyback converter is one such popular isolated DC-DC converter topology used to obtain regulated output voltage in low power applications. They are used as power supply systems in space technology and in many other industrial power electronics systems, where having constant voltage is very much essential. This paper presents the practical implementation of multiple output Flyback converter with MOSFET as a switching device. The designed converter is observed to have a good output voltage regulation and higher efficiency for the wide input voltage range.
\end{abstract}

Keywords - Flyback converter, multiple outputs, wide input voltage range, output regulation.

\section{INTRODUCTION}

DC-DC converters are mainly classified as non-isolated and isolated topologies. The classifications between isolated and non-isolated topologies are mainly w.r.t. presence of isolation transformer. Buck converter, Boost converter, Cuk converter, Buck-Boost converter, and Sepic converter fall under non-isolated converter topologies. Flyback, Forward, Push-Pull, Half-Bridge and Full-Bridge converters are taken into isolated converter topology groups [1].

In the case of Flyback converter topology, the converter stores the energy when the switch is on and delivers energy to the load when the switch is off. This eliminates the need of additional inductor for storage of energy unlike in the case of forwarding, half-bridge, and full-bridge topologies. Thus it makes the topology simpler and economical. Flyback converter can be designed to obtain single output and multiple outputs. The detailed analysis of single output, multiple output Flyback converters are provided [2].

The controller is the important component of DC-DC converter. They are mainly used to obtain regulated output voltage. Current mode control is one of the commonly used control technique which not only regulate the output voltage but also limits peak load current [2] - [4].

This research work aims at the design and implementation of multiple outputs $\mathrm{SiC}$ device based Flyback converter in discontinuous conduction mode. Hardware implementation is done considering design parameters and obtained results are analyzed.

\section{SIC TRANSISTORS}

As an of silicon carbide's favorable features, $\mathrm{SiC}$ power devices and power integrated systems can handle much higher power density compared with traditional silicon counterparts. This happens because SiC-based devices combine higher breakdown voltage with wider frequency bandwidth signals, allowing significant performance improvement in many applications such as radiofrequency, microwave and power electronics, with plenty of advantages offered by silicon carbide devices over silicon diodes, MOSFETs and another type of transistors currently on the market.[7]

\section{A. Advantages of using SiC transistors}

The main advantage of SiC MOSFET is low drain-tosource ON-resistance ( $\left.\mathrm{R}_{\mathrm{DS}-\mathrm{ON}}\right)$ - about 300-400 times lower than that of silicon devices with a comparable breakdown voltage - presenting a key desirable feature for designing extraordinarily efficient power electronics equipment and related systems.
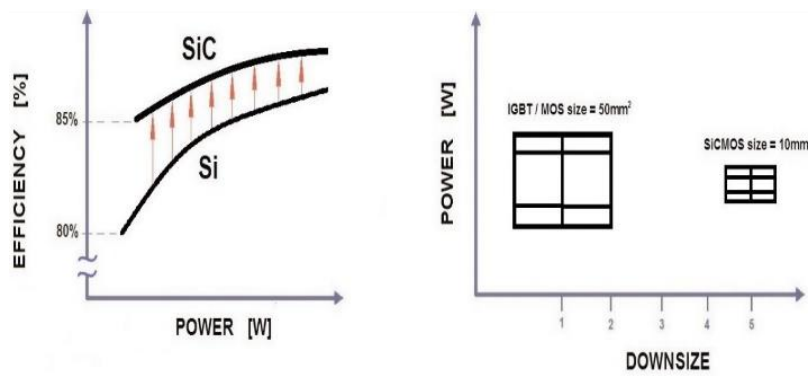

Fig. 1. Estimated efficiency and downsizing for SiC versus silicon devices.

Additionally, silicon carbide exhibits an operating temperature of at least $200{ }^{\circ} \mathrm{C}$, i.e. $50{ }^{\circ} \mathrm{C}$ higher than the absolute maximum rating of silicon MOS devices. Sometimes this temperature can go up to $400{ }^{\circ} \mathrm{C}$ or more.

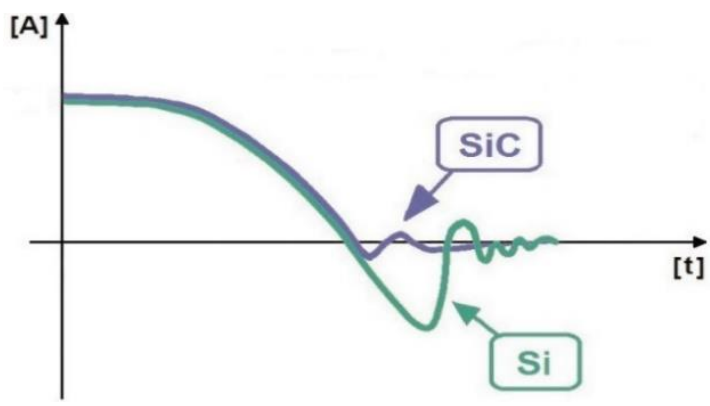

Fig. 2. Reverse recovery time.

The reverse recovery time of SiC SBDs is smaller and shorter than silicon fast recovery devices. Thanks to these 
better characteristics, the deployment of $\mathrm{SiC}$ diodes is going ahead and they are replacing silicon counterparts, particularly in a critical application operating at 600-1200V with current rating up to $50 \mathrm{~A}$, such as active PFC and other kinds of boost converters, UPS, motor drives, solar inverters, DC-to-DC primary stages.[7]

\section{MultiPle OUTPUT FlyBACK TOPOLOGY}

The basic multiple output Flyback converter topology in which one of the output $\left(V_{\text {out } 2}\right)$ is well regulated and second output $\left(V_{\text {outl }}\right)$ is quasi regulated is shown in Fig. 1. Regulation of output voltage at $V_{\text {out }}$ is effected by the loading on the $V_{\text {out } 2 \text {. Equations (1)-(2) give output voltages }}$ without considering diode drop.

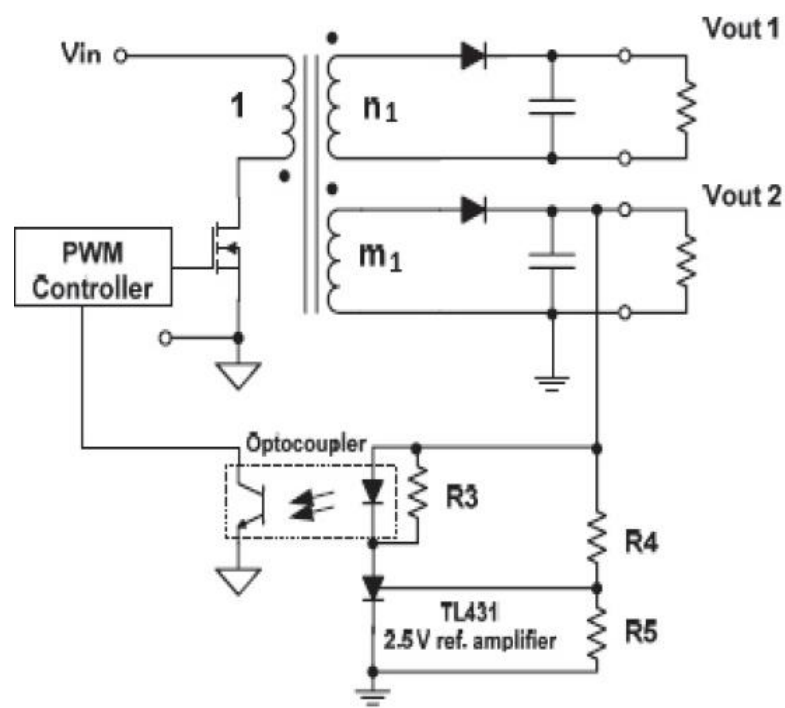

Fig. 3. Schematic of multiple output Flyback converter.

$$
\begin{gathered}
V_{\text {out } 1}=n_{1} \times\left(\frac{D}{1-D}\right) \times V_{\text {in }} \\
V_{\text {out } 2}=m_{2} \times(D / 1-D) \times V_{\text {in }}
\end{gathered}
$$

Witch considering diode drop the output voltage is given by (3):

$$
V_{\text {out } 1}=\left(n_{1} / m_{2}\right) \times\left(V_{\text {out } 2}+V_{d 2}\right)-V_{d 1}
$$

where $n, m$ are the number of turns in the secondary winding and tertiary winding. $V_{d l}, V_{d 2}$ are diode voltage drops and $D$ is the duty cycle.

When the MOSFET switch is closed for DT time the magnetizing inductance $\left(L_{m}\right)$ of the primary winding get energized. Due to the dot polarity of the windings connected, the output diodes are open-circuited. During the time, when the switch is opened, the stored energy in Lm forms voltage across the primary winding of the transformer $\left(V_{l}\right)$. The secondary voltage thus induced is rectified and produces the required output dc voltage [2].

\section{MultiPle OUTPUT FlYBACK TOPOLOGY}

\section{A. Application}

A typical block diagram of a Variable Frequency Drive (VFD) is shown in Fig. 4. As the block diagram shows, the DC link is connected to the inverter stage that varies the magnitude and frequency of the motor input voltage to produce the desired torque-speed characteristics from the motor.

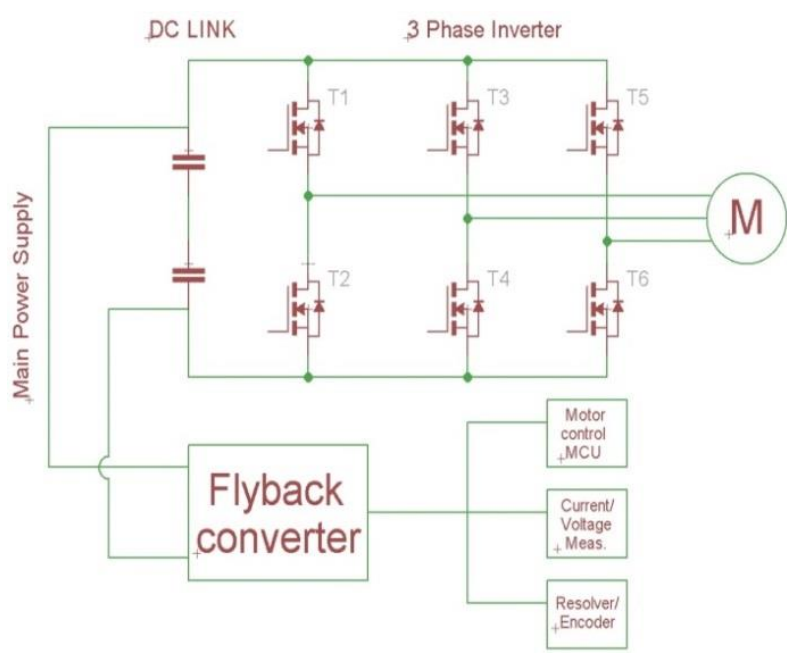

Fig. 4. Application of Flyback converter.

Fig. 4 shows that multiple low-voltage sub-systems in a VFD (like Motor control, MCU, current and voltage sensing, resolver, encoder and so forth) require DC power at different voltage levels including $15 \mathrm{~V}, \pm 15 \mathrm{~V}$ (symmetric), $12 \mathrm{~V}$ (bias supply). VFDs generally use one main power supply that feeds off the DC link and produces multiple output voltage rails that can be used to power the sub-systems directly or post downstream power processing. Thus, the main power supply in a VFD is a very critical sub-system and a potential single point of failure for the entire VFD unit. Hence, a robust main power supply that can operate reliably under harsh environments is imperative. Given the isolation and multiple output requirements, flyback is the topology of choice for the main power supply in VFDs.

Traditionally, main power supplies using flyback topology have been implemented using the UCx $84 x$ family of PWM controllers.

\section{B. Description of Multiple Output Flyback Converter}

Specifications of Flyback converter are provided in Table I. The converter is designed to operate in a wide input voltage range of $100 \mathrm{~V}-700 \mathrm{~V}$. It has three winding with an additional $12 \mathrm{~V}$ winding. Initially required startup current for the controller IC is given through the startup of the resistor. The controller generates a PWM signal that drives the gate of MOSFET. Once the converter operates in a steady-state, the generated $12 \mathrm{~V}$ output will take care of the required bias supply for the controller IC.

The Multiple output Flyback transformer parameters considered for the design converter circuit are shown in TABLE I. 
TABLE I.

KEY SYSTEM SPECIFICATIONS

\begin{tabular}{|c|l|l|}
\hline & Description & Specifications \\
\hline 1 & Output power ratings & $40 \mathrm{~W}$ \\
\hline 2 & Input voltage range $\mathrm{V}_{\text {in }}$ & $100 \mathrm{~V}-700 \mathrm{~V}$ \\
\hline 3 & Max. switching frequency $\left(\mathrm{F}_{\mathrm{sw}}\right)$ & $54 \mathrm{kHz}$ \\
\hline 4 & $\mathrm{~V}_{\text {out1 }}-$ regulated rail & $15 \mathrm{~V} / 2 \mathrm{~A}$ \\
\hline 5 & $\mathrm{~V}_{\text {out } 2-\text { symmetric output }}$ & $\pm 15 \mathrm{~V} / 0.3 \mathrm{~A}$ \\
\hline 6 & $\begin{array}{l}\text { Voltage consideration for bias } \\
\text { winding }\end{array}$ & $12 \mathrm{~V} / 0.2 \mathrm{~A}$ \\
\hline 7 & Magnetizing inductance $\left(\mathrm{L}_{\mathrm{p}}\right)$ & $800 \mu \mathrm{H}$ \\
\hline 8 & Regulation & Opto-regulated \\
\hline 9 & Protection & OV, OC limit, UV \\
\hline
\end{tabular}

\section{Constant-Voltage Constant-Current Flyback Controller Using Optocoupled Feedback}

The UCC28740 isolated-flyback power-supply controller provides Constant-Voltage (CV) using an optical coupler to improve transient response to large load steps. Constant-Current (CC) regulation is accomplished through Primary-Side Regulation (PSR) techniques. This device processes information from opto-coupled feedback and an auxiliary flyback winding for precise high-performance control of output voltage and current [5].

An internal $700 \mathrm{~V}$ startup switch, dynamically controlled operating states, and a tailored modulation profile support ultra-low standby power without sacrificing startup time or output transient response.

Control algorithms in the UCC28740 allow operating efficiencies to meet or exceed applicable standards. The drive output interfaces to a MOSFET power switch. Discontinuous conduction mode (DCM) with valleyswitching reduces switching losses. Modulation of switching frequency and primary current peak amplitude (FM and AM) keeps the conversion efficiency high across the entire load and line ranges.

The controller has a maximum switching frequency of $100 \mathrm{kHz}$ and always maintains control of the peak primary current in the transformer. Protection features keep primary and secondary component stresses in check. A minimum switching frequency of $170 \mathrm{~Hz}$ facilitates the achievement of less than $10 \mathrm{~mW}$ no-load power.

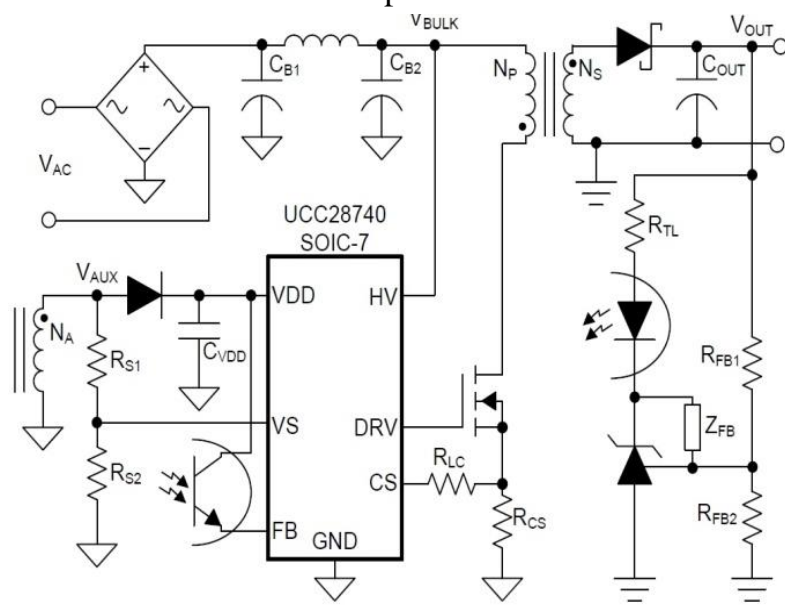

Fig. 5. Simplified application diagram of Flyback converter.

\section{DESIGN OF CIRCUIT COMPONENTS}

First of all, it was necessary to calculate the main circuit components such as transformer and consequently appropriately dimension semiconductor components (transistor, diodes)

\section{A. Design of Transformer}

The transformer design of the flyback converter is important in terms of voltage stress of semiconductor components and converter efficiency. Key design parameters are transformation ratio, magnetization induction, voltage and current values by windings. Some of the following calculations and some parameters are used from the flyback controller datasheet.

\section{1) Transformation ratio primary-to-secondary}

The equation (4) determines thread ratio between the primary winding and secondary windings

$$
N_{p s}=\left(D_{\text {max }} \times V_{\text {bulk_valley }}\right) /\left(D_{\text {demag }} \times\left(V_{\text {out }}+V_{f}\right)\right)
$$

where, $D_{\max }-$ maximum duty cycle, $D_{\text {demag }}-$ demagnetizing duty cycle, $\mathrm{V}_{\text {bulkvalley }}$ - minimal input voltage for start converter, $\mathrm{V}_{\text {out }}$ - regulated output voltage, $V_{f}$ - forward voltage drop secondary diode

\section{2) Current measurement}

Current is measured through a resistor which we calculate as follows:

$$
R_{c s}=\left(V_{c c r \_n o m} \times N_{p s} \times \sqrt{\eta_{t r}}\right) /\left(2 \times I_{o c c}\right)
$$

Where, $V_{\text {ccr_nom }}$ - is UCC28740 parameter, $\eta_{\text {tr }}$ - estimated efficiency of transformer, $\mathrm{I}_{\mathrm{occ}}-$ current in $\mathrm{CCM}\left(\mathrm{I}_{\text {out }} * 1,15\right)$

Then the maximum current allowed by the primary winding after which the converter goes into CC mode is given by:

$$
I_{\text {prim_max }}=\frac{V_{\text {cst_nom }}}{R_{C S}}
$$

\section{3) Magnetization induction}

The magnetization induction of the primary winding is given by (5)

$$
L_{p}=\frac{2 \times\left(V_{\text {out }}+V_{f}\right) \times I_{o c c}}{\eta_{\text {tran }} \times\left(I_{\text {prim_max }}\right)^{2} \times F_{s w}}
$$

\section{B. Design of Magnetic Circuit}

In the given types of switched power supplies, ferrite cores are often used as magnetic circuits. They have specific and suitable characteristics for high-frequency applications $(10 \mathrm{kHz}$ ) of lower power (up to $500 \mathrm{~W}$ ). They show lower saturation $\mathrm{B}<0.5 \mathrm{~T}$. In this chapter, we focused on the physical design of the transformer in terms of the 
number of windings of the windings, the determination of the wire cross-section and the selection of the cube.

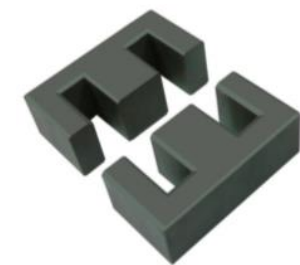

Fig. 6. Ferrite core E32/16/9.

1) Calculation of the minimum number of turns of the primary winding

$$
N_{p}=\frac{L_{p} \times I_{o c c}}{B_{\max } \times A_{e}}
$$

If the integer does not work, then round up the resulting value.

2) Calculation of the minimum number of turns of the secondary winding

If we know the number of turns of the primary winding and the ratio between the primary and secondary windings we can calculate the number of turns of the secondary winding as shown in equation 9 :

$$
N_{s}=\frac{N_{p}}{N_{p s}}
$$

Repeat the procedure for all secondary windings.

3) Calculating the air gap

To calculate the air gap we need to know the following parameters:

\section{Magnetic conductivity for the core}

$$
\Lambda=\frac{L_{p}}{N_{p}^{2}}
$$

Magnetic resistance for an air gap core

$$
\mathrm{R}_{m}=\frac{1}{\Lambda}
$$

Magnetic resistance of ferrite core calculated from its parameters

$$
\mathrm{R}_{F e}=\frac{1}{\mu_{r} \times \mu_{0}} \times \frac{l_{F e}}{A_{e}}
$$

\section{Air gap resistance}

$$
\mathrm{R}_{v}=R_{m}-R_{F e}
$$

Air gap calculation

$$
l_{g}=R_{v} \times A_{e} \times \mu_{0}
$$

4) Calculation of wire diameter and winding area

Example calculation of wire diameter and area for primary winding:

Required wire cross-section content depending on the current density of copper

$$
S_{d}=\frac{I_{\text {prim } \_r m s}}{J_{d}}
$$

\section{Calculation of wire diameter}

$$
D_{d}=2 \times \sqrt{\frac{S_{d}}{\pi}}
$$

Total wire surface area including all primary turns

$$
S_{\text {prim }}=\pi \times\left(\frac{D_{d}}{2}\right)^{2}
$$

It should be noted, however, that we need to maintain the insulating voltage strength of the primary side to the secondary side for increased safety and this is achieved by selecting higher insulation of the wire of either the primary or secondary side.

\section{5) Determination of transformer 'window' area and fill factor}

This step tells us whether the cube or core will be large enough to fit all the windings. Otherwise, we would have to repeat the design process of the transformer and select a larger core, respectively smaller. The area of the "window" is determined according to Fig. 7, where the blue color shows the core and the green area of the window, which we need to know in order to be able to calculate the filling factor. We can see that the calculation in our case is simple, which consists only of the content of the rectangle (sides a, b). However, this may not always be the case because it depends on the shape and size of the core or cube.

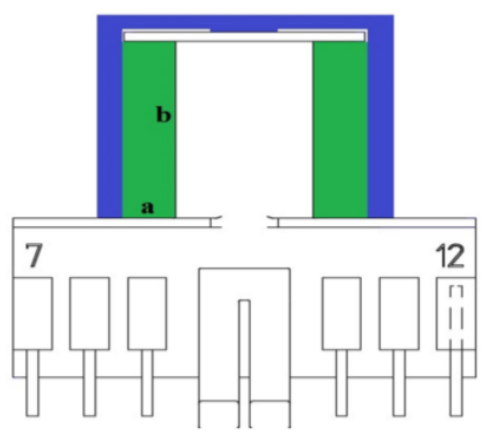

Fig. 7. Window area. 
Filling factor is given by equation 18 :

$$
S_{\text {prim }}=\frac{S_{\text {prim }}+S_{a}+S_{\text {sekn }}}{S_{w}}
$$

The recommended maximum fill factor is $0.4-0.5$. This is due to the fact that in the calculation we consider the ideal placement of the wire and do not consider the tape to isolate the individual windings from each other.

There is no uniform way to properly wind the transformer to exhibit the best properties and to eliminate stray inductance. However, this can be significantly reduced by appropriate layer layouts and suitably "bind" them.

The recommended procedure for reducing the leakage inductance is as follows - as the first part on the cube we wound half of the primary coils. For better bonding, it is advisable to wind the most loaded secondary branch as close as possible to the primary winding. Secondary winding with symmetrical output was wound bifilar. Then on top, we finished the second half of the secondary winding.

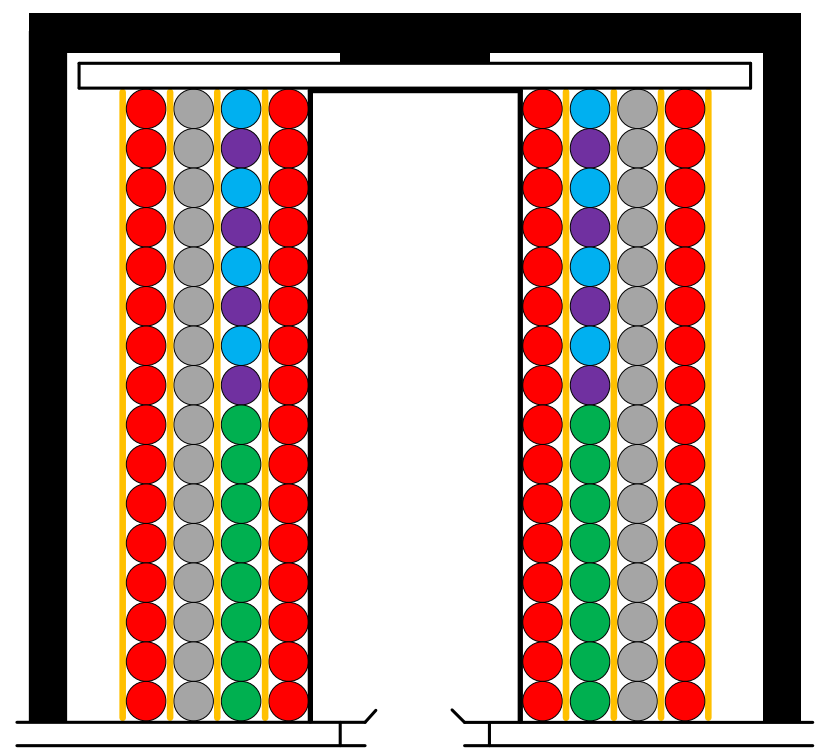

Fig. 8. Winding layout.

- $\quad$ Red - primary winding

- Blue/purple - secondary symmetrical winding $( \pm 15 \mathrm{~V})$

- Green - secondary main winding (15 V)

- Gray - auxiliary winding (12 V)

- Yellow - insulation tape

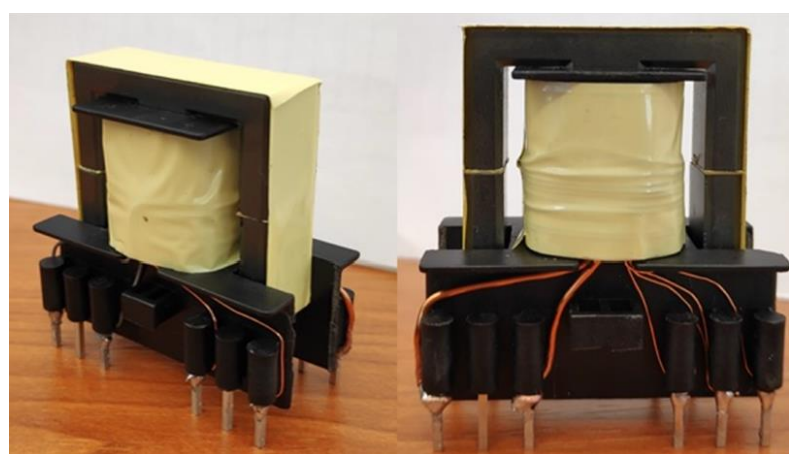

Fig. 9. Real sample of transformer.

The main transformer parameters are specified in TABLE II.

TABLE II.

MULTIPLE OUTPUT FLYBACK TRANSFORMER PARAMETERS

\begin{tabular}{|l|l|l|}
\hline & Description & Specifications \\
\hline 1 & Primary turns $\left(\mathrm{N}_{1}\right)$ & 76 \\
\hline 2 & $\mathrm{~V}_{\text {out1 winding turns }\left(\mathrm{N}_{2}\right)}$ & 10 \\
\hline 3 & $\mathrm{~V}_{\text {out2 }}$ winding turns $\left(\mathrm{N}_{3}\right)$ & 13 \\
\hline 4 & $\mathrm{~V}_{\text {out3 winding turns }\left(\mathrm{N}_{4}\right)}$ & 13 \\
\hline 5 & Bias winding turns & 8 \\
\hline 6 & Transformer core $(\mathrm{E})$ & Ferrite 32/16/9 \\
\hline 7 & Prim. max current $\left(\mathrm{I}_{\text {prim_max }}\right)$ & $1,38 \mathrm{~A}$ \\
\hline 8 & Prim. mag. Induction $\left(\mathrm{L}_{\mathrm{p}}\right)$ & $860 \mu \mathrm{H}$ \\
\hline & &
\end{tabular}

\section{Design of Semiconductor Components}

From the transformer design, we know the flowing currents of the given windings and we know the transformation conditions, so we can determine what the voltage and current stresses of the semiconductor elements will be.

\section{1) Design of primary transistor}

The transistor works as a master switch, so in the blocking state, the maximum input voltage is added to the reflective voltage and the peak overvoltage caused by the leakage inductance. The maximum voltage $\mathrm{V}_{\mathrm{DS}}$ is given by the equation 19:

$$
V_{D S}=V_{\text {in_max }}+N_{p s} \times\left(V_{\text {out }}+V_{f}\right) \times 2
$$

$\mathrm{N}_{\mathrm{ps}}\left(\mathrm{V}_{\text {out_cv }}+\mathrm{V}_{\mathrm{f}}\right)$ in the equation represents the reflective voltage and is considered twice because it is assumed that the surge caused by the leakage inductance is equal to the reflective voltage.

The transistor should be designed for a $V_{D S}$ voltage and a maximum current Iprim_max, that can flow through the primary winding. If we consider the highest input voltage, which is $700 \mathrm{~V}$, then the maximum voltage $\mathrm{V}_{\mathrm{DS}}$ would be $950 \mathrm{~V}$. However, this is limit values and it is necessary to select a transistor with higher blocking voltage. We can decide for two options: 
a) Use two switch topology

We can use two classic MOSFET-s with voltage up to $600 \mathrm{~V}$ connected in series to achieve blocking voltage up to $1200 \mathrm{~V}$. The disadvantage is that compensation is needed to achieve that the voltage is distributed evenly between the two gets.

b) Use single switch topology with high blocking voltage usually SiC

The advantage is that you only need to use one switching element because $\mathrm{SiC}$ has a blocking voltage of $1200 \mathrm{~V}$. But $\mathrm{SiC}$ topology is relatively new and therefore more expensive.

We used a single switch topology, but CoolMOS was used as the switch because we had limited conditions and tested the converter up to $300 \mathrm{~V}$. Fig. 10 shows the voltage waveform of the primary transistor. From this waveform, we can read the value of the reflective voltage, which is $116 \mathrm{~V}$. We got a reflection voltage of $125 \mathrm{~V}$ by calculation.

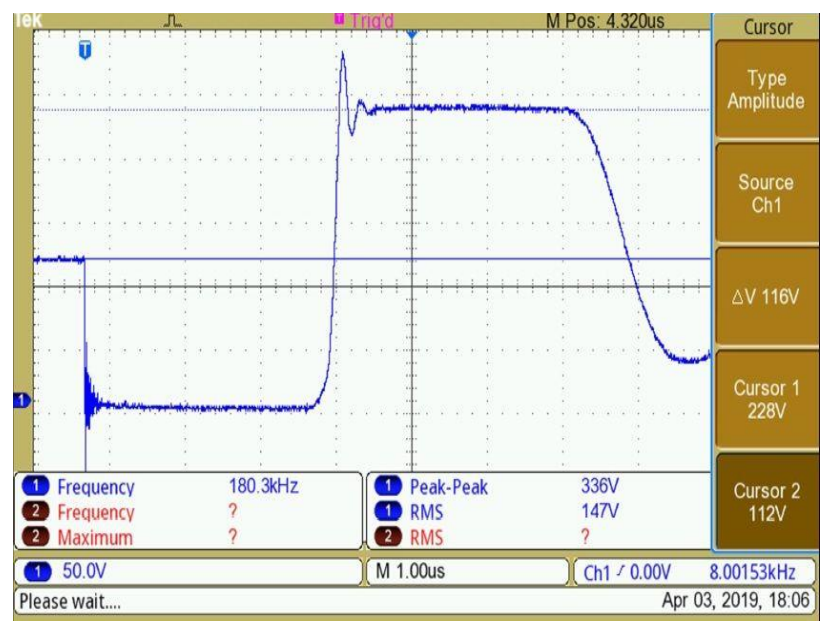

Fig. 10. Voltage waveform on the primary.

\section{2) Design of secondary diode}

Secondary diode was selected based on reverse voltage appearing across the diode, secondary RMS current and secondary peak current.

Reverse voltage (Vr) appearing across diode when the MOSFET is on, is given by:

$$
V_{r}=V_{\text {out }}+\frac{V_{\text {in_max }}}{N_{p s}}
$$

where, Vin_max - maximum input voltage, N1 - turns of primary winding, $\mathrm{N} 2$ - turns of secondary winding, Vout - voltage of secondary output.

Secondary peak current is given by:

$$
I_{\text {sec_pk }}=\frac{P_{\text {out }} \times 2}{V_{\text {out }} \times D_{\text {demag }}}
$$

\section{Secondary RMS value current is given by:}

$$
I_{\text {sec } \_r m s}=I_{p k} \sqrt{\frac{D_{d e m a g}}{3}}
$$

Repeat the procedure for all secondary diodes.

\section{HARDWARE IMPLEMENTATION}

This reference design is a robust, compact, wide-input flyback converter using the UCC28740 device. The UCC28740 device is a constant current, constant voltage flyback controller with opto-regulation. Therefore, UCC28740 is an ideal fit for the main power supply for VFDs. Fig. 4 shows that the reference design takes in an input voltage in the range of $100-700 V_{D C}$ via a fuse and diode. A fuse protects against overcurrent and a diode protects against the reversal of input voltage polarity. Three aluminum electrolytic capacitors, connected in series, are used as a bulk DC link to reduce input current ripple. The primary winding terminals of the flyback transformer are connected to the positive terminal of the DC link and the drain of the primary MOSFET, respectively. The auxiliary winding of the flyback transformer serves two key purposes - one, to provide an equivalent signal of the output voltage for output $\mathrm{OV}$ fault detection, valley switching, output current regulation during $\mathrm{CC}$ mode and two, to provide (rectified) power to the VDD pin of UCC28740. The secondary side of the flyback transformer has 3 windings $+15 \mathrm{~V}(2 \mathrm{~A}),+15 \mathrm{~V}(0.3 \mathrm{~A}),-15 \mathrm{~V}(0.3 \mathrm{~A})$.

The key part in the reference design is the flyback controller, the UCC28740 device. The self-start feature is implemented via the HV pin which is directly connected to one-third of the DC link voltage and enables self- start through a current source generated by the internal HV FET. The primary-side current sense resistor is connected between the source of the primary MOSFET and PGND (DC link) and feeds into the CS pin - this enables input peak current control. The primary MOSFET is driven by pulses from the DRV pin through a push-pull configuration to enable higher gate current (limited by gate resistors) operation. The output voltage is sensed via the resistor divider connected across the auxiliary winding and fed into the VS pin for output OV fault detection. Opto-regulated feedback is fed into the FB pin for accurate output voltage regulation.

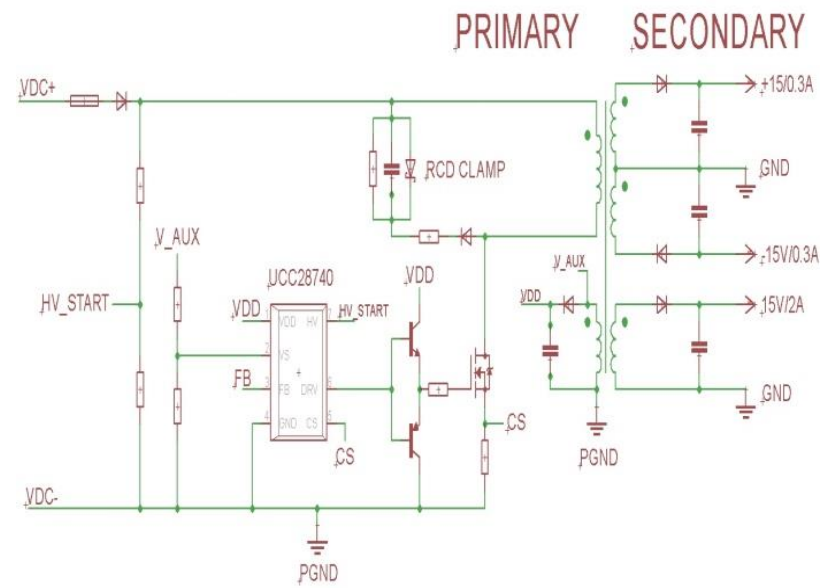

Fig. 11. Scheme of multiple output Flyback converter. 


\section{EXPERIMENTAL RESULTS}

Fig. 12 shows the layout of PCB of the multiple output Flyback converter designed for specified Variable Frequency Drive (VFD). The PCB design has a specific shape that must be followed in order to fit it onto the inverter board.

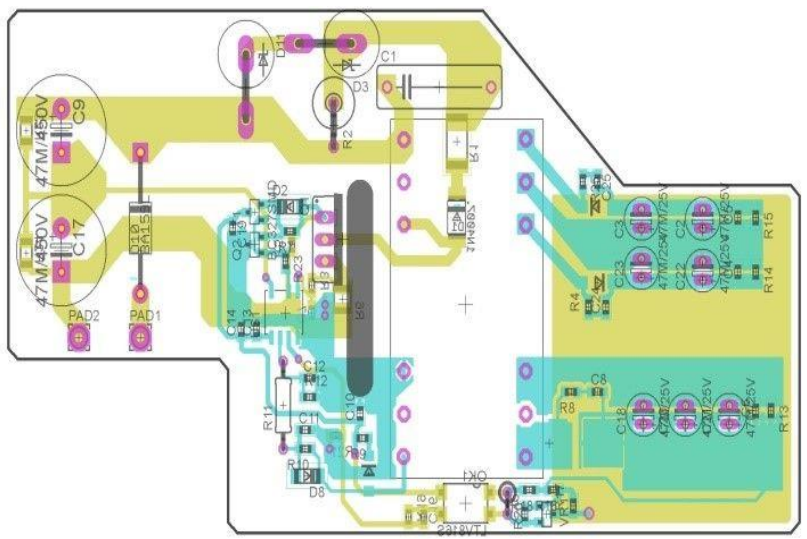

Fig. 12. Efficiency of multiple output Flyback converter.

Fig. 13 shows the measurement of efficiency at two input voltages $150 \mathrm{~V}$ and $300 \mathrm{~V}$. The full load efficiency was greater than $85 \%$.

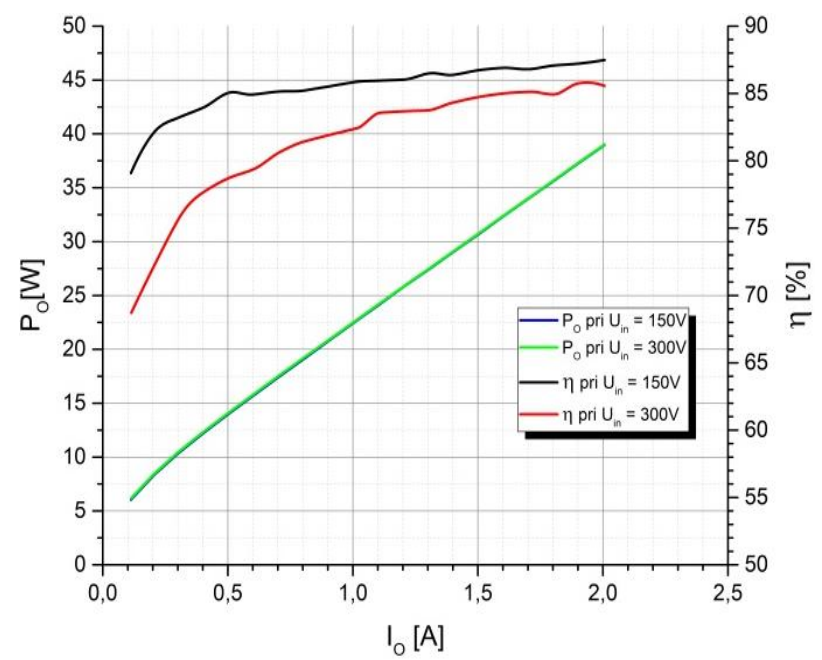

Fig. 13. Efficiency of multiple output Flyback converter.

Fig. 14 shows output characteristic of multiple output flyback converter, where the blue line is regulated the output voltage. Red and black waveforms are unregulated output voltages. We can see that the blue waveform has a constant voltage but the red and black wave does not. This is because feedback is only fed to one output. This phenomenon can be eliminated by cross-regulation.

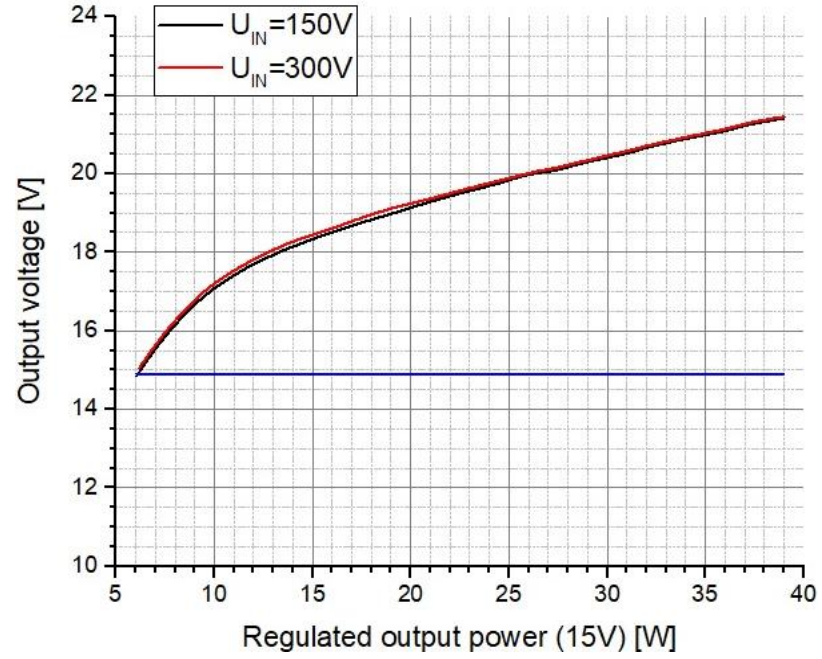

Fig. 14. The output characteristic of multiple output Flyback converter.

Fig. 15-16 show the startup of multiple output Flyback converter, where Fig. 15 represents when the converter is without load and Fig. 16 represents when the converter is at full load.

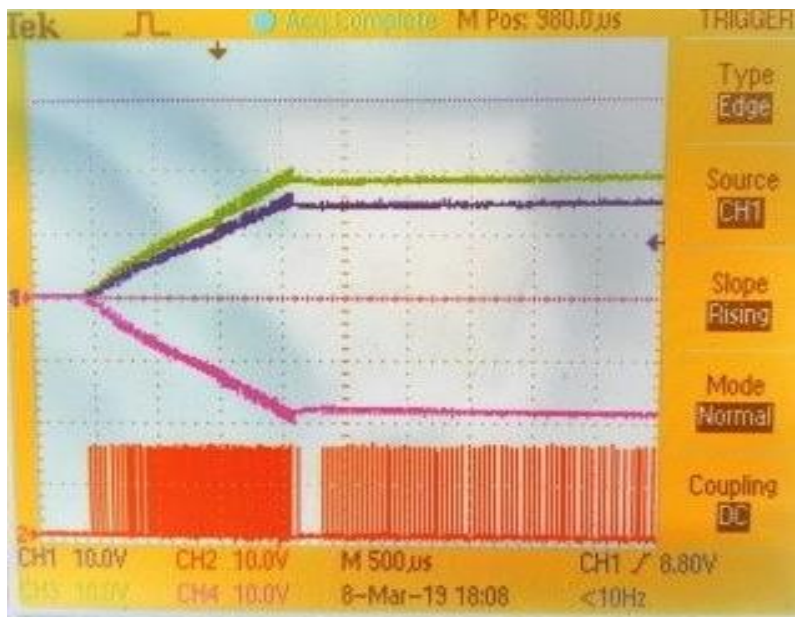

Fig. 15 Startup of multiple output Flyback converter Noload.

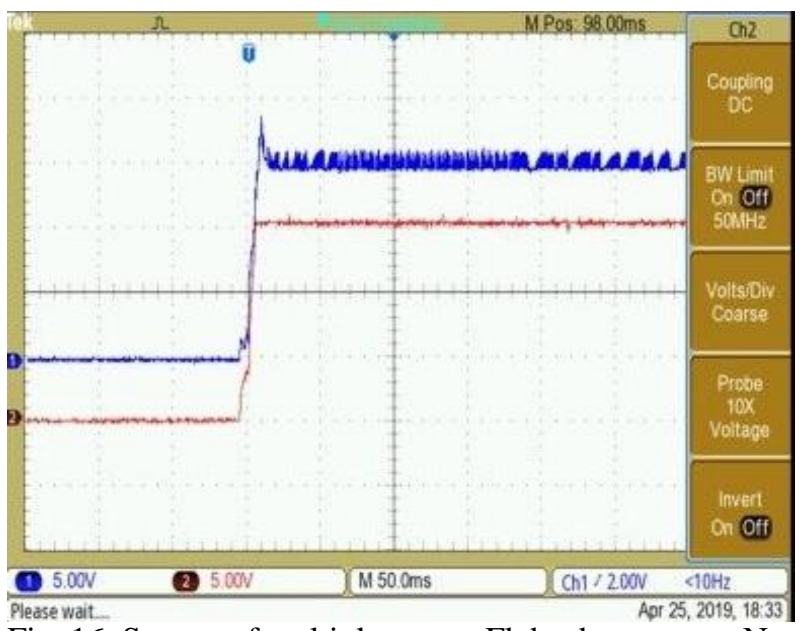

Fig. 16. Startup of multiple output Flyback converter Noload. 
Fig. 17 shows output ripple voltage on regulated output, were at full load ripple voltage was $700 \mathrm{mV}$.

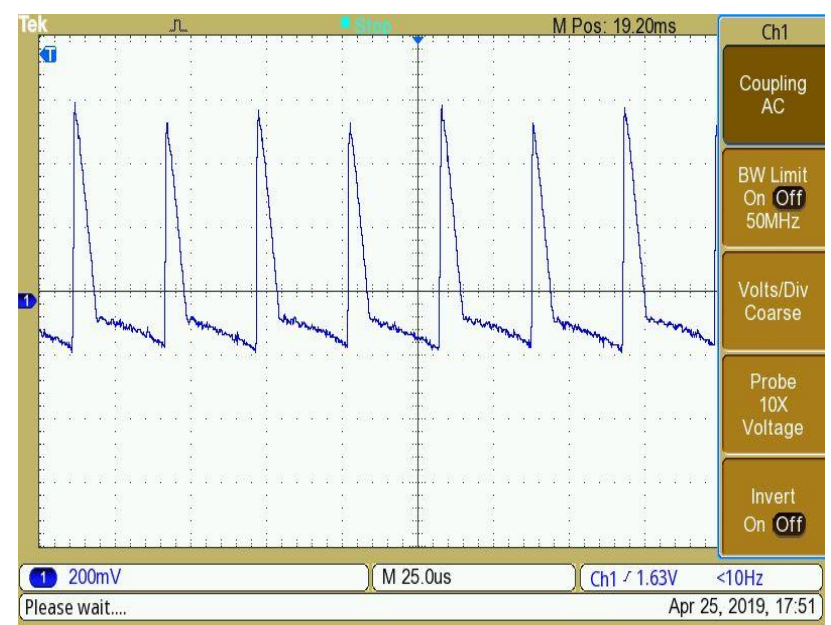

Fig. 17. Output ripple voltage of converter.

\section{CONCLUSION}

This article deals with the design of multiple output auxiliary power supply realized by Flyback topology for specified Variable Frequency Drive (VFD). It includes calculations for the design and selection of circuit components such as the primary MOSFET transistor, output diodes, and finally experimental results. This paper deals with the design of an isolated converter test sample tested up to $300 \mathrm{~V}$ but can also be used as a design guide for a Flyback power supply with $700 \mathrm{~V}$ input where SiC transistor can be implemented.

\section{ACKNOWLEDGMENT}

This work was supported by project VEGA 1/0119/18.

\section{REFERENCES}

[1] B. M. Wilamowski, J. D. Irwin, "Power Electronics and Motor Drives", CRC Press, 2017. https://doi.org/10.1201/9781315218410

[2] C. Nagesha, A. Sreedevi, and Muniraj Gopal, "Simulation and Hardware Implementation of 24 Watt Multiple Output Flyback Converter", in International Conference on Power and Advanced Control Engineering, 2015.

https://doi.org/10.1109/ICPACE.2015.7274974

[3] C. Mullett and F. Cathell, "Improving the Regulation of MultiOutput Flyback Converters", in Twenty-Fourth Annual IEEE Applied Power Electronics Conference and Exposition, 2009. https://doi.org/10.1109/APEC.2009.4802935

[4] R. Ridley, "Flyback Converter Snubber Design", Switching Power Magazine, 2006

[5] Texas Instruments, "50-W Opto-Regulated Multi-Output Flyback Converter Snubber Design”, Reference Design for 380-480 VAC Motor Drives, TIDA-010000.

[6] R. Radvan, B. Dobrucky, M. Frivaldsky, and P. Rafajdus, "Modelling and Design of HF $200 \mathrm{kHz}$ Transformers for Hard - and Soft-Switching Application", Electronics and Electrical Engineering, No.4 (110), pp.7-12, 2011. https://doi.org/10.5755/j01.eee.110.4.276

[7] G. Vacca, "Benefits and advantages of silicon carbide power devices their silicon counterparts", Semiconductor today, Vol.12 (72), pp.4$5,2017$. 